\title{
Quão confiáveis podem ser os modelos físicos em escala reduzida para avaliar a iluminação natural em edifícios?
}

How reliable are small-scale physical models in the evaluation of daylight in buildings?

\section{Fernando Oscar Ruttkay Pereira Roberto Carlos Pereira Alexander González Castaño}

\section{Resumo}

Fernando Oscar Ruttkay Pereira Departamento de Arquitetura e Urbanismo, Centro Tecnológico Universidade Federal de Santa Catarina Caixa-Postal 476 Trindade Florianopolis - SC - Brasil CEP 88040-900 Tel.: (48) 3721-7080 E-mail: feco@arq.ufsc.br

Roberto Carlos Pereira Campus Rio Grande Instituto Federal do Rio Grande do Sul

Rua Alfredo Huch, 475 CEP 96201-460

Tel.: (53) 3233-8603 E-mail: roberto. pereira@riogrande.ifrs. edu.br

Alexander González Castaño Departamento de Arquitetura e Urbanismo, Centro Tecnológico Universidade Federal de Santa Catarina E-mail: alexander@univ.co

Recebido em 01/10/11 Aceito em 24/11/11
A

iluminação natural apresenta-se como uma das estratégias individuais de maior potencial para a redução do consumo de energia nos edifícios. Para a realização desse potencial é essencial caracterizar precisa e quantitativamente o ambiente luminoso. Há várias décadas, modelos físicos em escala reduzida tem sido empregado para a avaliação da iluminação natural. Entretanto, apesar dos benefícios, o método tem sido alvo de críticas que apontam os erros encontrados como sendo deficiências intrínsecas dele. Este estudo visa avaliar duas das fontes de erro mais citadas: medição sob condições de céu real, e o efeito de escala. O estudo foi desenvolvido em duas etapas: (a) comparação de iluminâncias medidas simultaneamente num ambiente real e num modelo físico em escala reduzida, expostos ao céu real; e (b) comparação de iluminâncias medidas em modelos físicos construídos em três diferentes escalas, submetidos a um céu artificial do tipo "caixa de espelhos”. Na primeira etapa, os erros foram inferiores a 5\%, exceto naquelas situações em que a componente refletida foi relevante. Na segunda etapa, os resultados foram ainda melhores, mostrando uma insignificância do efeito de escala, com divergências inferiores a 4\%. Através deste estudo, é possível afirmar que o método é confiável, desde que cuidados sejam tomados na confecção dos modelos e nas medições, em especial no que tange às propriedades ópticas das superfícies, condições de exposição dos modelos (entorno), precisão dimensional e procedimentos fotométricos.

Palavras-chave: Iluminação natural. Método experimental. Modelos físicos.

\section{Abstract}

Daylight is one of the individual strategies with greatest potential for reducing energy consumption in buildings. To realize this potential it is essential to characterize the environment precisely and quantitatively. For decades, reducedscale physical models has been employed for daylight evaluation. However, despite its benefits, this method has been the target of criticisms that have pointed out errors as intrinsic shortcomings. This study aims to evaluate two of the most cited sources of error: measurement under real sky conditions, and the effect of scale. The study was divided into two stages: (a) comparison of illuminances measured simultaneously in a real environment and a physical model in reduced scale, exposed to the real sky; and (b) comparison of illuminances measured in physical models built in three different scales subjected to an artificial "mirror box"-type sky. In the first stage, the results showed errors less than 5\%, except in those situations where the reflected component was relevant. In the second step, the results were even better, showing that the scale effect was insignificant, with differences less than 4\%. The results clearly indicate that this method is reliable, provided care is taken in producing the models and the measurements, especially regarding the optical properties of the surfaces, the conditions of exposure models (surroundings), dimensional accuracy, and photometric procedures.

Keywords: Daylight. Experimental method. Physical models. 


\section{Introdução}

Modelos físicos em escala reduzida são ferramentas utilizadas para avaliar a iluminação natural no processo de projeto desde que os seres humanos decidiram não viver mais em cavernas, mas construir sua própria habitação. Esses modelos, também usualmente chamados pelos arquitetos de maquetes, são ferramentas de projeto que os arquitetos têm empregado há muito tempo para explorar e estudar diferentes aspectos do projeto e construção de edificações. Eles fazem parte do processo de criação e entendimento do espaço físico, superando a bidimensionalidade dos desenhos. Representam as três dimensões do espaço, e, com uma correta proporção, uma ideia de produto tem como ser transmitida para outras pessoas (GONZÁLEZ CASTAÑO, 2007).
Os modelos físicos também contribuem para o desenvolvimento dos projetos, para a quantificação de peças e elementos de fabricação ou industrialização. Os grandes mestres da arquitetura moderna, como Louis I. Kahn, Alvar Aalto, Le Corbusier e Frank Lloyd Wright, construíram e usaram maquetes no desenvolvimento de seus projetos para estudo e apresentação final para colegas e clientes (Figuras 1 e 2).

A prática das maquetes não se limita à representação de uma imagem do projeto. As maquetes podem ser ferramentas de simulação de fenômenos físicos avaliados qualitativa e quantitativamente, tais como ventilação, geometria solar, comportamento estrutural e, especialmente, o fenômeno da iluminação.

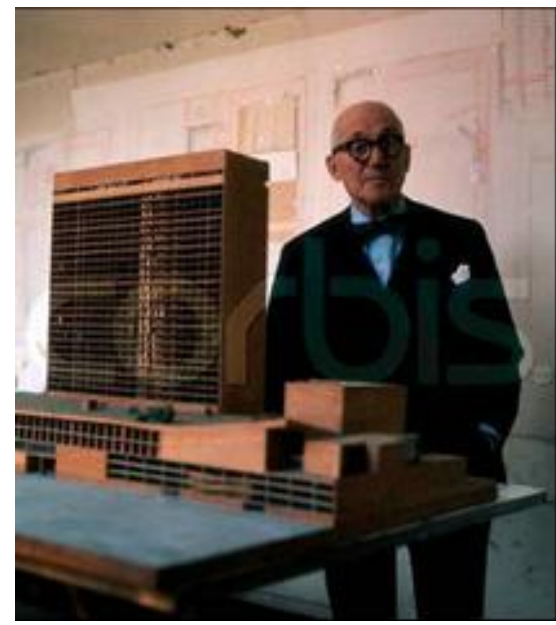

Figura 1 - Le Corbusier, ca. 1950-1965

Fonte: foto de Almasy (ca. 1950-1965).

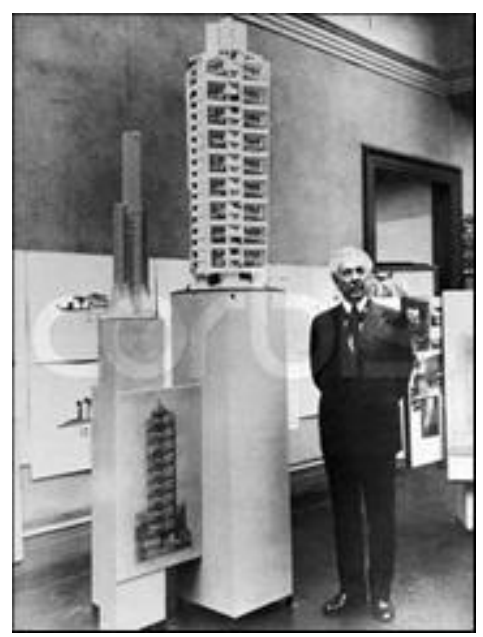

Figura 2 - Frank Lloyd Wright, em 1930

Fonte: Corbis Images (2012). 
A literatura científica na área é categórica ao afirmar que, ao contrário de outros modelos físicos nos quais o comportamento do fenômeno físico (transmissão de calor, tensões estruturais, fluxo de ar, etc.) sofre distorções pelo efeito da escala, o modelo para iluminação natural não requer compensações em função da escala. Um modelo físico em escala reduzida que replica perfeitamente um espaço real, exposto às mesmas condições de céu, apresenta um padrão de distribuição da iluminação interna idêntico. Isso é devido ao fato de o comprimento de onda da luz visível ser extremamente reduzido em comparação ao tamanho dos modelos em escala reduzida; assim, a luz reflete nas superfícies internas do modelo da mesma forma que no espaço real (BAKER; STEEMERS, 2002). Vários pesquisadores têm reportado uma correlação bastante alta entre resultados obtidos em ambientes reais e os obtidos em modelos em escala reduzida (KIM; BOYER; DEGELMAN, 1985; BODART; DENEYER; MOENSSENS, 2004).

As principais vantagens do estudo através de modelos físicos em escala reduzida são:

(a) proporciona a obtenção de dados quantitativos precisos, mesmo com modelos simplificados;

(b) é adequado para lidar com geometrias complexas;

(c) permite comparações expeditas pela possibilidade de troca de componentes;

(d) mesmo com modelos simples, possibilita avaliações qualitativas mediante observação direta ou por fotografias;

(e) é familiar para a maioria dos arquitetos; e

(f) é didático e serve como ferramenta de comunicação com outros membros da equipe e clientes.

Talvez a razão mais importante de se construírem modelos físicos de iluminação natural seja porque eles podem responder a questões sobre diferentes aspectos do projeto do ambiente construído além da iluminação natural. Dados quantitativos são usados para avaliar a eficácia da iluminação natural em atender a exigências visuais, e projeções sobre necessidades de iluminação artificial podem também ser feitas por meio desses dados. Dados qualitativos podem ajudar na definição do conforto visual e na percepção clara das características espaciais do ambiente interno.

Uma vantagem dos modelos físicos sobre modelagem computacional torna-se aparente quando se consideram situações reais de projeto: muitos ambientes não são formados por simples planos retangulares ou por materiais com propriedades fotométricas conhecidas, especialmente aqueles projetados para fazer o melhor uso da luz natural (NASPOLINI; PEREIRA， 2004; MARDALJEVIC， 2004; REINHART; FITZ, 2006). Programas de computador que conseguem lidar com geometrias complexas (Genelux, Radiance, Dialux, AGI32, Apolux, etc.) não são muito "amigáveis" no que diz respeito à modelagem do ambiente. Com modelos físicos, não apenas geometrias complexas podem ser analisadas, mas modificações simples de geometria podem ser efetuadas com peças intercambiáveis, e os resultados podem ser avaliados de forma expedita tanto por seus efeitos visuais como pelos níveis de iluminação resultantes.

Resultados bastante úteis podem ser alcançados com pouco investimento se a escala e os detalhes do modelo estiverem adequados às questões a serem respondidas - em outras palavras, não construa um modelo perfeito e elegante para responder a uma pergunta simples. A consideração orçamentária mais importante é a integração das questões e estudos de iluminação natural durante os diversos estágios do processo de projeto arquitetônico. Questões respondidas adequadamente e cedo nesse processo (por exemplo, balanço entre iluminação natural, sombreamento e insolação) podem evitar a necessidade e/ou a elevação de gastos posteriores (por exemplo, equipamento de ar condicionado mais potente, maior consumo de energia elétrica para iluminação artificial, etc.). Recomendações sobre escalas adequadas (ver Quadro 1) e cuidados a serem tomados para a construção e teste dos modelos podem ser encontrados em bibliografia específica (PEREIRA, 1995; BAKER; STEEMERS, 2002).

Entretanto, deve-se considerar que, para o desenvolvimento de avaliações quantitativas precisas, é também necessário contar com instrumentação fotométrica adequada, aspecto que pode limitar esse exercício só a laboratórios especializados e a grandes escritórios profissionais, pelo custo dos equipamentos. Esse método também requer tempo elevado para o desenvolvimento das avaliações (MOORE, 1991; SCHILER, 1987; KIM; BOYER; DEGELMAN, 1985). 


\begin{tabular}{|c|c|c|c|}
\hline \multicolumn{4}{|c|}{ ESTUDOS DE ILUMINAÇÃO COM MAQUETES EM ESCALA } \\
\hline ESTUDO & ESCALA & OBJETIVO & DETALHES \\
\hline $\begin{array}{l}\text { MODELAGEM } \\
\text { DO ENTORNO }\end{array}$ & $1: 500-1: 100$ & $\begin{array}{l}\text { Formular a resposta das edificaçóes ao seu } \\
\text { entorno: } \\
\text { - Modelar as condições locais de acesso à luz } \\
\text { natural e distribuiçẫo dos edificios. } \\
\text { - Modelar condiçốes de céu claro, encoberto e luz } \\
\text { solar. } \\
\text { - Modelar diferentes configurações volumétricas. }\end{array}$ & $\begin{array}{l}\text { - Geometria da edificaçăo e } \\
\text { entorno. } \\
\text { - Refletāncias das superficies } \\
\text { do entorno e edificaçõ̂es } \\
\text { adequadas. } \\
\text { - Aberturas desenhadas nas } \\
\text { fachadas. }\end{array}$ \\
\hline \multirow{3}{*}{$\begin{array}{l}\text { FORMATO DE } \\
\text { ABERTURAS }\end{array}$} & \multirow{3}{*}{$1: 50-1: 30$} & \multirow{3}{*}{$\begin{array}{l}\text { Desenvolver o envoltório para analisar } \\
\text { exigèncias internas diante das condiçooes } \\
\text { externas: } \\
\text { - Modelar formas e tamanhos das aberturas para } \\
\text { avaliar seu desempenho luminoso. } \\
\text { - Modelar outros sistemas (estrutural, ar- } \\
\text { condicionado) para avaliar sua integração com } \\
\text { diferentes aberturas. } \\
\text { - Modelar formas de superficies interlores e avaliar } \\
\text { sua habilidade em distribuir luz natural. }\end{array}$} & $\begin{array}{l}\text { - Precisão na geometria dos } \\
\text { componentes do edificio e } \\
\text { divisórias internas. }\end{array}$ \\
\hline & & & $\begin{array}{l}\text { - Precisão na geometria dos } \\
\text { sistemas de aberturas. }\end{array}$ \\
\hline & & & - Refletânclas precisas. \\
\hline \multirow{5}{*}{$\begin{array}{l}\text { TRATAMENTO } \\
\text { DO } \\
\text { ENVOLTÓRIO }\end{array}$} & \multirow{5}{*}{$1: 25-1: 15$} & $\begin{array}{l}\text { Modificar o projeto de iluminação natural } \\
\text { através de detalhes de envoltório: }\end{array}$ & $\begin{array}{l}\text { - Detalhes precisos dos } \\
\text { elementos das aberturas e }\end{array}$ \\
\hline & & $\begin{array}{l}\text { - Modelar elementos acessórios das aberturas } \\
\text { para avaliar seu efeito na admissão de luz natural. }\end{array}$ & $\begin{array}{l}\text { fontes de luz. } \\
\text { - Todo o interior deve ser }\end{array}$ \\
\hline & & - Modelar envidraçados. & possivel. \\
\hline & & \begin{tabular}{|l|} 
- Modelar efeito de cortinas, persianas, etc. \\
- Modelar sistemas de iluminaçăo artificial.
\end{tabular} & $\begin{array}{l}\text { - Esquadrias devem mostrar } \\
\text { os detalhes construtivos. }\end{array}$ \\
\hline & & $\begin{array}{l}\text { - Determinar niveis de iluminaçăo para adequaçăo } \\
\text { de sistemas de controle de iluminação artificial. }\end{array}$ & $\begin{array}{l}\text { - Mobiliário importante deve } \\
\text { ser adequadamente modelado }\end{array}$ \\
\hline $\begin{array}{l}\text { AMBIENTE } \\
\text { INTERNO }\end{array}$ & $\begin{array}{l}1: 10 \text { ou } \\
\text { maior }\end{array}$ & $\begin{array}{l}\text { Modelar a réplica exata dos detalhes do } \\
\text { interior e caracteristicas espaciais. }\end{array}$ & $\begin{array}{l}\text { - Modelar o mais precisamente } \\
\text { possível os detalhes. }\end{array}$ \\
\hline
\end{tabular}

Quadro 1 - Tipos de estudos de iluminação com modelos reduzidos

Nota: adaptado de Pereira (1995).

Os testes de iluminação com modelos físicos em escala reduzida podem ser desenvolvidos sob céu real ou sob céu artificial. Para avaliações qualitativas, os testes sob céu real são recomendados pela distribuição de suas luminâncias, reprodução das cores e qualidade que apresenta a luz do dia, proveniente da abóbada celeste. Os testes qualitativos de iluminação sob céus reais permitem fazer avaliações conjuntas da incidência solar nos projetos, usando-se um simples relógio solar construído para a latitude do local do projeto. Assim, é possível verificar de forma expedita o funcionamento conjunto e a efetividade dos sistemas de iluminação e controle da radiação solar direta.

Para avaliações quantitativas de iluminação, as condições de variabilidade do céu real podem afetar consideravelmente o levantamento de dados de iluminação no interior dos modelos. A variabilidade das luminâncias medidas da abóbada celeste pode ser de até $15 \%$, mesmo em dias aparentemente idênticos (MOORE, 1991). Essa condição introduz nos estudos de iluminação a dependência do fenômeno climático, sendo pouco efetivas essas análises em função do maior tempo necessário para sua realização e consideração das transformações fotométricas da abóbada.

Um dos principais obstáculos encontrados na simulação com modelos físicos, durante décadas, tem sido o ceticismo de alguns profissionais com relação à confiabilidade dos resultados produzidos. Enquanto os cálculos analíticos, para uma mesma configuração, produzem sempre os mesmos valores numéricos, os experimentos utilizando modelos físicos podem apresentar resultados de medições aparentemente não muito precisas, podendo ser afetados pela dispersão dos dados, o que, na verdade, caracteriza a maioria dos procedimentos experimentais.

Experimentos feitos por Mardaljevic (2002) mostraram erros de avaliações com maquetes sob céu real encoberto superiores a 50\%. Para céus claros foram estimados erros de $100 \%$ a $250 \%$ entre a maquete e o edifício real monitorado. Sob céus reais ocorre maior dependência dos fenômenos ambientais, com variabilidade maior

134 Pereira, F. O. R.; Pereira, R. C.; González Castaño, A. 
nos níveis de iluminação. No Quadro 2 são apresentados os principais fatores do erro para avaliação quantitativa de iluminação com maquetes em escala.

Como uma resposta às dificuldades de estudo sob céus reais, céus artificiais têm sido empregados há décadas. A principal vantagem é ter a garantia de condições confiáveis e reproduzíveis para simular o ambiente luminoso externo (EVANS; BAROLDI; MARMORA, 1997). Por serem ambientes com iluminação padronizada e controlada, os céus artificiais garantem o desenvolvimento de avaliações quantitativas de iluminação natural e a possibilidade de se compararem estudos desenvolvidos em diferentes simuladores. Esses equipamentos têm sido desenvolvidos e utilizados em centros de pesquisa e escolas de arquitetura para aplicações acadêmicas e profissionais. Existem diversos modelos de céus artificiais. Quanto a sua forma, podem ser classificados em dois tipos: hemisféricos e retangulares. Os primeiros podem simular distribuição de luminâncias complexas, tais como as do céu claro (inclusive a luz direta do sol), e os segundos - o mais conhecido é o do tipo “caixa de espelhos” - simulam a distribuição do céu encoberto. Diversos céus artificiais têm sido propostos nos últimos anos; a maioria busca expandir as possibilidades de simulação de diferentes distribuições de luminâncias (BAKER; STEEMERS, 2002; NAVVAB, 1995; MOORE, 1991; COOKSY et al., 1989; BODART, 2004).

Atualmente, muitos pesquisadores, segundo Thanachareonkit, Andersen e Scartezzini (2005), consideram que os erros da imprecisão na construção de maquetes possam ser elevados, mas eles são mais frequentes quando as maquetes são expostas a condições de céus reais. Sob céus artificiais os erros são menores, fazendo com que esse método seja competitivo em sua qualidade diante de outros métodos de avaliação quantitativa de iluminação natural. Mesmo assim, ainda existe muito ceticismo e desconfiança pelos resultados obtidos em avaliações com modelos físicos em escala reduzida expostos a céus reais e artificiais, em especial devido à falta de atenção para com muitos dos principais fatores físicos de erros apresentados no Quadro 2. Um dos fatores que costuma estar no topo da lista das causas de erro é o efeito de escala: seria este mesmo nulo? Quais as distorções máximas? Enfim, para dar uma resposta a parte desses questionamentos, desenvolveu-se o presente estudo.

\begin{tabular}{|c|c|c|}
\hline Fatores físicos & $\begin{array}{c}\text { Divergência relativa entre } \\
\text { escala reduzida } x \text { real }\end{array}$ & $\begin{array}{c}\text { Referência } \\
\text { bibliográfica }\end{array}$ \\
\hline $\begin{array}{l}\text { Detalhes do modelo } \\
\text { Opacidade das paredes } \\
\text { Efeito da escala } \\
\text { Refletâncias das superfícies } \\
\text { Vazamentos de luz }\end{array}$ & Não há dados disponíveis & Schiler (1987) \\
\hline $\begin{array}{l}\text { Calibração dos sensores } \\
\text { Refletâncias das superfícies } \\
\text { Reprodução do modelo e entorno } \\
\text { Detalhes das aberturas } \\
\text { Tamanho dos sensores } \\
\text { Faixa de medição dos sensores } \\
\text { Posicionamento dos sensores }\end{array}$ & $30 \%$ a $50 \%$ & Love e Navvab (1991) \\
\hline $\begin{array}{l}\text { Precisão dimensional } \\
\text { Efeito da escala } \\
\text { Reprodução do entorno } \\
\text { Refletâncias das superfícies } \\
\text { Transmitância dos envidraçados } \\
\text { Manutenção e limpeza }\end{array}$ & $10 \%$ a $25 \%$ & $\begin{array}{c}\text { Cannon-Brookes } \\
\text { (1997) }\end{array}$ \\
\hline \multirow{2}{*}{$\begin{array}{l}\text { Exposição a céus reais } \\
\text { Tamanho dos sensores } \\
\text { Posicionamento dos sensores } \\
\text { Calibração dos sensores } \\
\text { Sensibilidade a deslocamentos } \\
\text { Precisão e tempo de resposta da } \\
\text { instrumentação }\end{array}$} & Até $50 \%$ sob céus encobertos & \multirow{2}{*}{ Mardaljevic (2002) } \\
\hline & $100 \%$ a $250 \%$ sob céus claros & \\
\hline
\end{tabular}

Quadro 2 - Fatores de erro entre método experimental com modelos em escala e a situação real 


\section{Objetivo}

O objetivo do presente trabalho consiste em avaliar a capacidade de modelos físicos em escala reduzida de simular a iluminação natural em ambientes reais e a influência da escala do modelo físico nos valores da iluminâncias internas medidas num céu artificial do tipo "caixa de espelhos".

\section{Método}

O método proposto baseia-se em duas etapas:

(a) comparação de iluminâncias medidas de forma simultânea em ambiente real e em modelo físico em escala reduzida, ambos expostos ao céu real; e

(b) comparação de iluminâncias medidas em modelos físicos construídos em três diferentes escalas, submetidos à iluminação de um céu artificial do tipo "caixa de espelhos”.

Cabe salientar que o presente estudo fez parte de uma avaliação mais abrangente, cujo principal objetivo foi desenvolver procedimentos para avaliação/validação de ferramentas de simulação computacional da iluminação natural baseados em mapeamento digital da distribuição de luminâncias da abóbada celeste, conforme descrito na Figura 3 (PEREIRA, 2009).

\section{Objetos de estudo: ambiente real $x$ ambiente em escala reduzida}

O estudo foi realizado no prédio da sede do Departamento de Arquitetura e Urbanismo da Universidade Federal de Santa Catarina (UFSC), na cidade de Florianópolis. A Figura 4 mostra a localização do prédio no campus da UFSC, e a Figura 5 apresenta a fachada e o arranjo de suas janelas orientadas para o sul. Na janela superior, à direita, localiza-se o ambiente real. Na esquerda, outro ambiente, com sua abertura destinada a posicionar o modelo físico em escala.

$\mathrm{O}$ ambiente real (ver Figura 8) tem comprimento de $4 \mathrm{~m}$, largura de 2,10 m, pé-direito de 3,0 m e apresenta paredes de cor branca, piso de cor palha, e teto de cor alecrim, com refletâncias conhecidas respectivamente por $75 \%$, $64 \%$ e $34 \%$. A sala foi pintada com tintas da fabricante Suvinil.

O ambiente possui uma única janela $(0,75 \times 0,75$ $\mathrm{m})$, disposta a $1,05 \mathrm{~m}$ do piso, centralizada na parede frontal em relação à entrada.

Localizados em uma linha central, no piso da sala, foram montados cinco sensores Li-Cor 210SA, conectados a um sistema de aquisição de dados DL2-DeltaT (ver Figuras 6 e 7). A calibração das fotocélulas foi realizada com um sistema portátil de calibração de sensores, denominado LI-1800-02 da Li-Cor (PEREIRA, 2009).

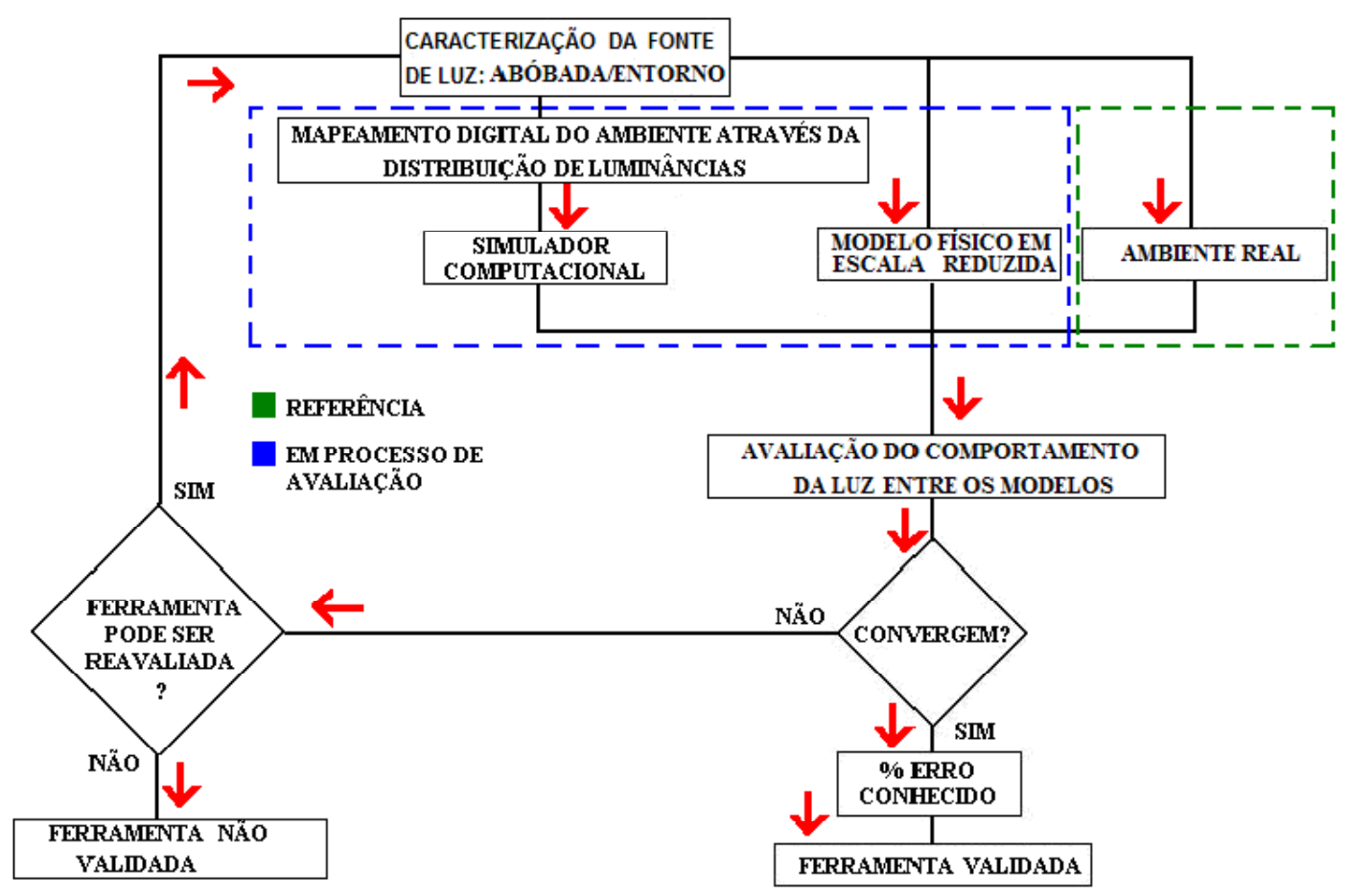

Figura 3 - Procedimentos esquemáticos para avaliação do desempenho de ferramentas computacionais e experimentais com modelos físicos em escala reduzida

Fonte: Pereira (2009).

136 Pereira, F. O. R.; Pereira, R. C.; González Castaño, A. 


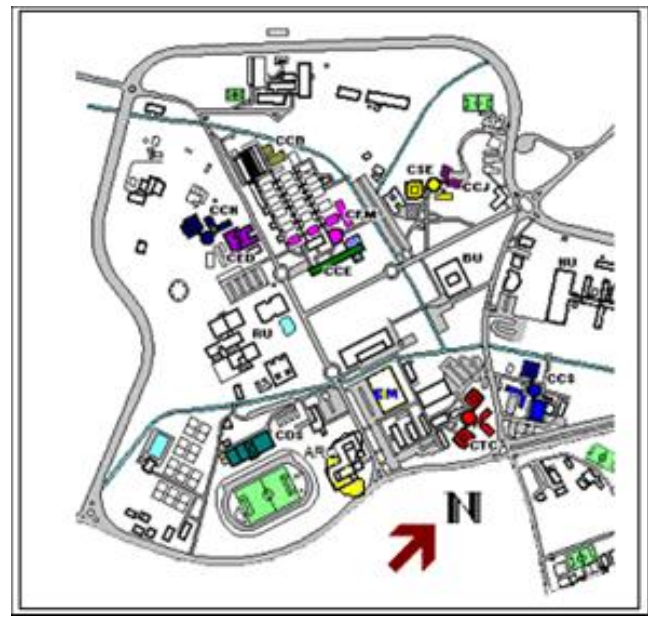

Figura 4 - Localização do prédio da Arquitetura no campus da UFSC

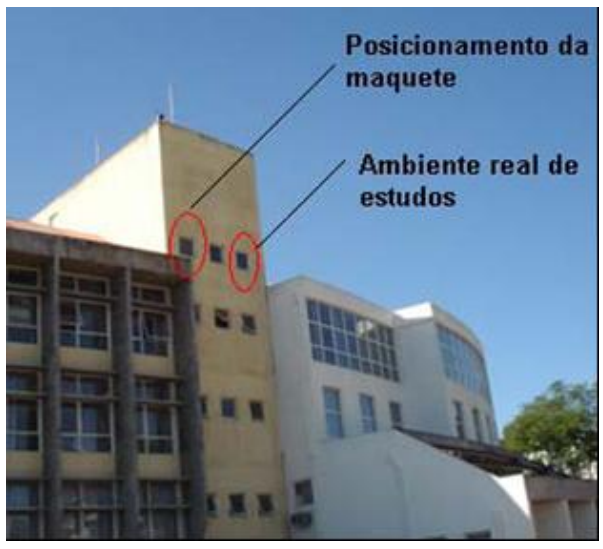

Figura 5 - Localização do ambiente real e o arranjo de suas janelas orientadas para o sul

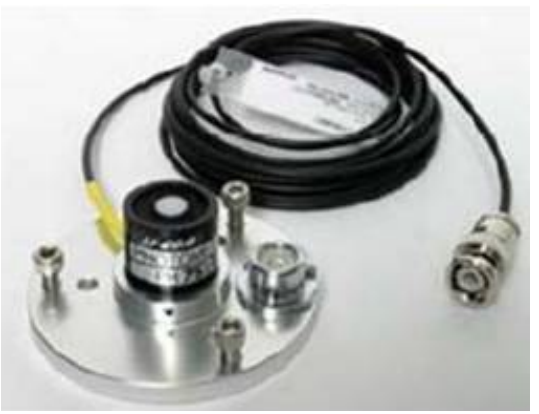

Figura 6 - Sensor Li-Cor 210SA

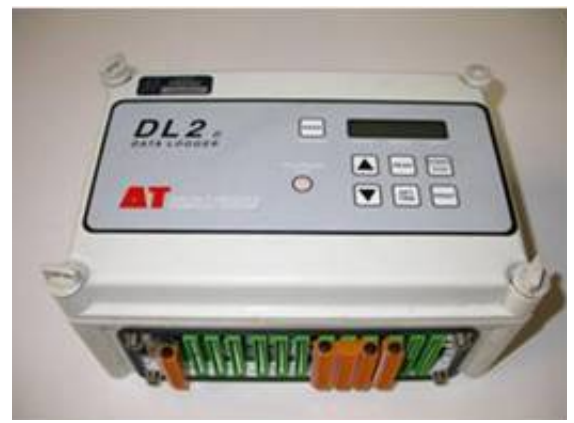

Figura 7 - Sistema de aquisição de dados DL2-DeltaT 


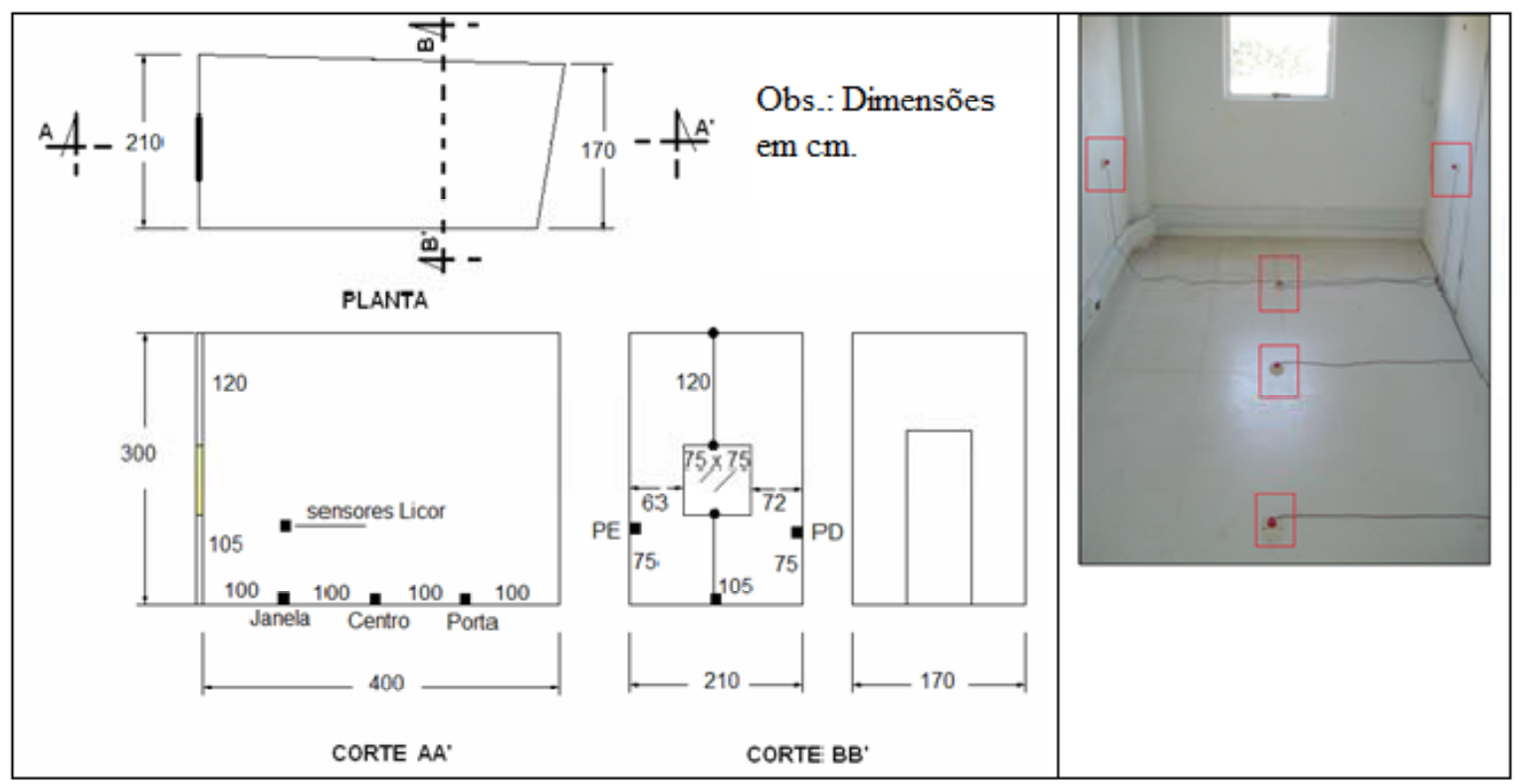

Figura 8 - Planta, cortes e foto do ambiente real, com a disposição dos sensores fotométricos

O primeiro sensor estava disposto a $1,0 \mathrm{~m}$ da janela; outro, no centro da sala, e o terceiro, a 3,0 $\mathrm{m}$ da janela. Além desses, colocaram-se dois sensores no plano vertical, com a finalidade de medir a iluminância nas paredes direita e esquerda da sala, a uma altura de $0,75 \mathrm{~m}$ do piso. Parte dessas disposições segue orientação da IEA (INTERNATIONAL..., 2006), que, através da Tarefa 21, sugere o posicionamento dos sensores em sistemas que utilizam luz natural. Essa distribuição foi repetida no modelo físico em escala reduzida.

O modelo físico foi construído em escala 1:5, de chapa de madeira de compensado, com $2 \mathrm{~cm}$ de espessura. Apresenta acesso ao interior através de aberturas no piso e no teto. Para os registros fotográficos, fez-se uma abertura circular no fundo do modelo (ver Figura 9).

Essas características proporcionam total flexibilidade para a colocação dos sensores Li-Cor 210SA, facilitando as medições de iluminâncias em seu interior. A espessura do compensado permite que os sensores fiquem embutidos, no mesmo plano do piso e da parede da maquete. Tal qual na sala real, foram dispostos cinco sensores, três com espaçamentos simétricos de $20 \mathrm{~cm}$ ao longo do comprimento do modelo, e dois verticais (paredes direita e esquerda), com uma altura de 15 cm (ver Figura 10a).

A Figura 10b mostra a maquete no céu artificial do tipo "caixa de espelhos"; e a Figura 10c, quando submetida ao céu real e entorno natural. Nessa segunda situação, o modelo é colocado em um recinto fechado de 2,5x1,3 $\mathrm{m}$, em uma janela ao lado do ambiente de estudos, nivelado e projetado para fora do prédio, com a finalidade de aproximar o ângulo de visão do exterior observado no ambiente real.

A maquete apresenta materiais com as mesmas propriedades de refletância da sala de estudo. As paredes, o teto e o piso foram cobertos por tinta Suvinil de refletâncias conhecidas, iguais respectivamente a 75\%, 34\% e 64\%. As medições do comportamento luminoso no ambiente real e no modelo físico foram realizadas sem a presença do vidro da abertura. Esse procedimento evitou possíveis distorções caracterizadas pela transmitância e especularidade do material, difíceis de ser modeladas no modelo em escala. Cabe salientar que o modelo físico em escala foi recoberto com papel preto para reduzir a interferência das reflexões externas na caracterização do ambiente luminoso interno do céu artificial, conforme recomendado por González Castaño (2007).

Foram realizadas 25 medidas entre os dias 02/02/2007 e 12/04/2008, em horários que variaram de $08 \mathrm{~h} 30$ a $15 \mathrm{~h} 00$, com distintas condições de céu. Além das medidas de iluminâncias, também foi realizado o mapeamento digital das luminâncias da abóbada celeste, para fins de validação de ferramentas de simulação computacional (PEREIRA, 2009). As medidas foram feitas em periodicidade aleatória. 


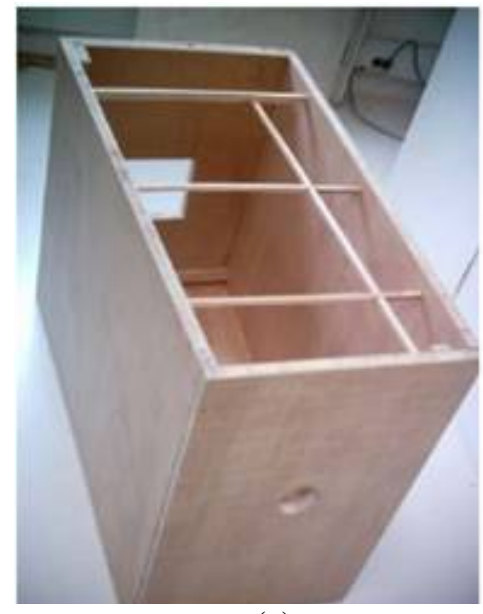

(a)

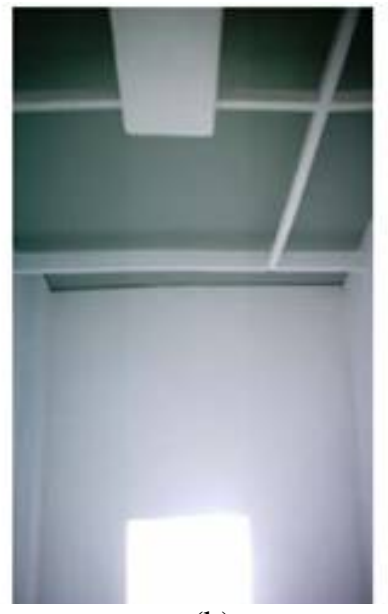

(b)

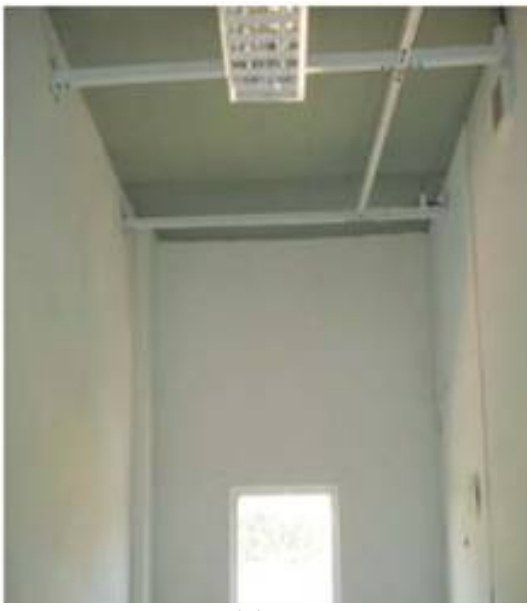

(c)

Figura 9 - (a) Modelo em construção; (b) Vista interna do modelo (teto); e (c) Foto interna do ambiente real

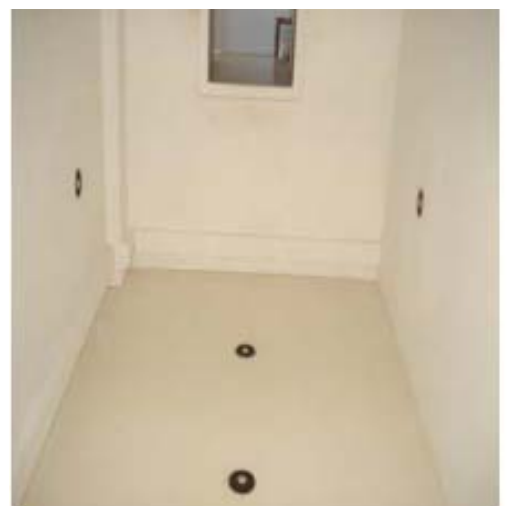

(a)

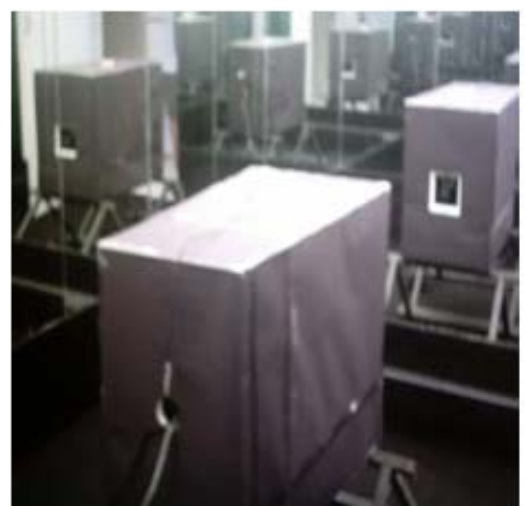

(b)

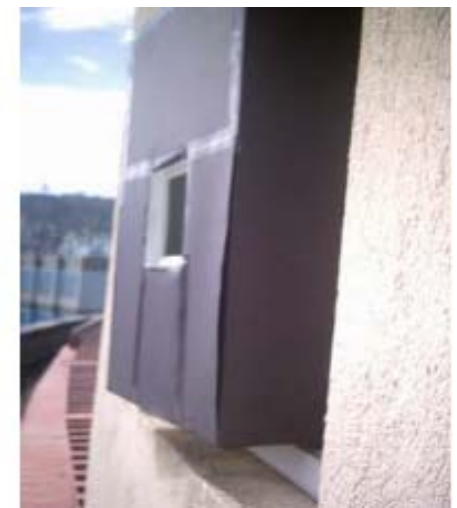

(c)

Figura 10 - (a) Posicionamento dos sensores na maquete; (b) Posicionamento da maquete para medição no céu artificial; e (c) Posicionamento da maquete para a medição no céu real + entorno

\section{Céu artificial do tipo "caixa de espelhos"}

O céu artificial do tipo "caixa de espelhos" do LabCon/ARQ/UFSC foi construído em 2005, no contexto do Projeto de Revitalização/Capacitação do LabCon-UFSC, com apoio financeiro da Eletrobras/Procel Edifica. Céus artificiais do tipo “caixa de espelhos” são constituídos conforme esquema mostrado na Figura 11, com um sistema de iluminação artificial superior coberto por um forro difusor e com as quatro paredes revestidas com placas de espelhos. O céu do LabCon/ARQ consiste num ambiente com 2,44 m de largura,
2,44 m de comprimento e 2,60 m de altura (ver Figura 12).

O céu foi calibrado em 2006 com o auxílio de um sistema de mapeamento digital de luminâncias IQCam Lumetrix (ver Figura 13), que possibilitou a caracterização precisa da distribuição de luminâncias do simulador, proporcionando sua calibração para produzir uma distribuição de luz semelhante à do Céu Encoberto CIE, conforme se verifica na Figura 14 (GONZÁLEZ CASTAÑO, 2007). 


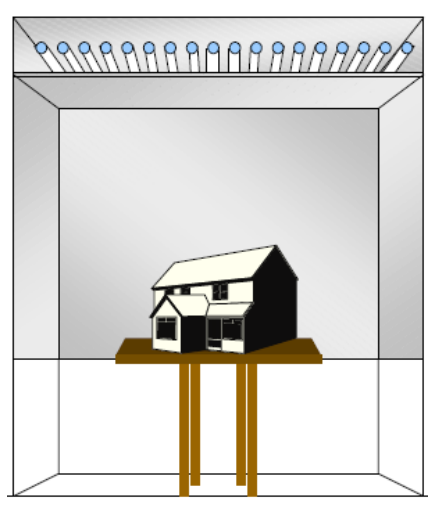

Figura 11 - Desenho esquemático do céu artificial do tipo "caixa de espelhos" Fonte: Bodart, Deneyer e Moenssens (2004).

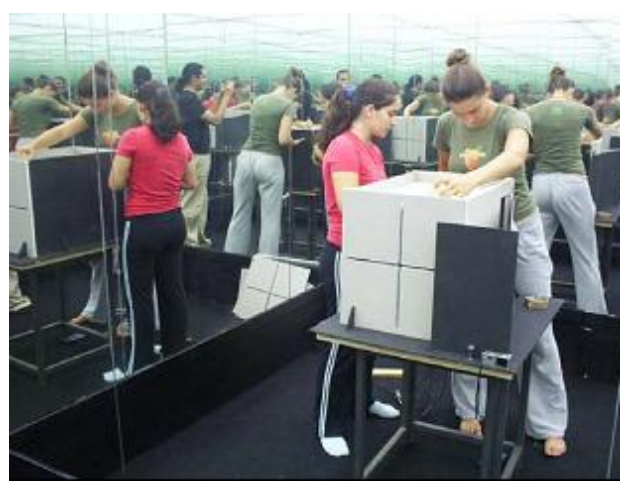

Figura 12 - Estudo em desenvolvimento no céu artificial do tipo "caixa de espelhos" do LabCon/ARQ

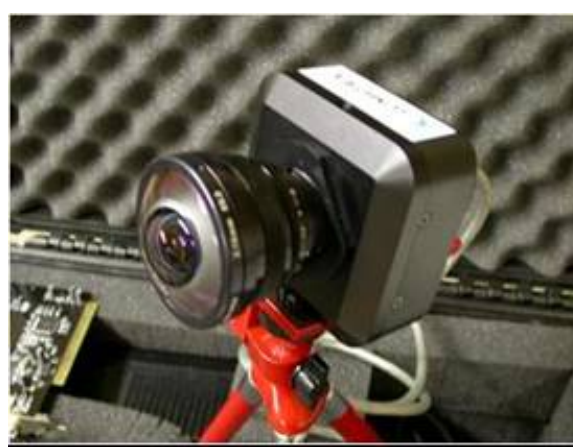

Figura 13 - Sistema de mapeamento digital IQCam da Lumetrix

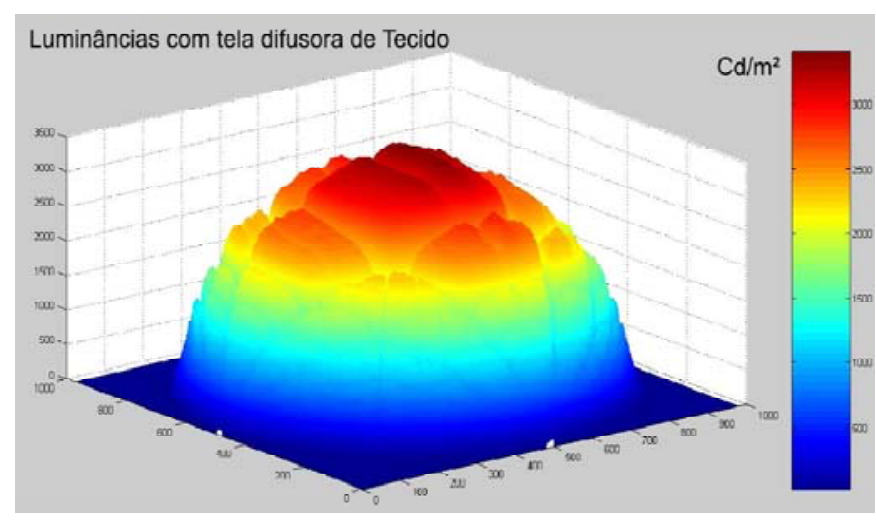

Figura 14 - Distribuição de luminâncias (em 3D) do céu artificial LabCon/ARQ já calibrado, semelhante à distribuição de um Céu Encoberto CIE

140 Pereira, F. O. R.; Pereira, R. C.; González Castaño, A. 


\section{Avaliação do efeito de escala}

O efeito de escala no estudo da iluminação com modelos arquitetônicos é apontado por muitos pesquisadores como uma das prováveis fontes de erro desse método (THANACHAREONKIT; ANDERSEN; SCARTEZZINI, 2005). Esse aspecto foi analisado como uma das principais determinantes na construção dos modelos arquitetônicos. Para esta investigação foram construídos três modelos arquitetônicos, em escalas 1:5, 1:7.5 e 1:10, para serem avaliados no céu artificial do LabCon/ARQ (ver Figura 15).

No interior de cada modelo arquitetônico foram demarcados três pontos para a instalação das fotocélulas Li-Cor, conservando sua respectiva relação entre a distância e a abertura, na escala e na localização deles no piso de cada modelo arquitetônico. O posicionamento dos modelos arquitetônicos foi determinado mantendo-se como referência para todos os casos a localização do centro geométrico da janela, orientada na direção de uma das paredes do céu artificial.

Todos os dados registrados no interior dos modelos arquitetônicos foram processados com a iluminância horizontal exterior para determinação do parâmetro DF (Daylight Factor).

\section{Análise dos resultados}

\section{Comparação dos resultados no ambiente real $x$ ambiente em escala reduzida}

As divergências nas medidas foram avaliadas através do erro relativo, conforme a Equação 1.
Erro $\mathrm{M}=\frac{E_{A R}-E_{M}}{E_{A R}} 100(\%)$

Eq. 1

Onde:

Erro $\mathrm{M}$ é o erro relativo das medidas feitas no ambiente em escala em relação às do ambiente real [\%];

$E_{A R}$ é a iluminância [lx] medida no ambiente real; e $E_{M}$ é a iluminância [lx] medida no ambiente em escala reduzida.

Inicialmente, as Figuras 16, 17 e 18 apresentam os valores medidos das iluminâncias EAR e EM nos 25 instantes de avaliação, para os três pontos no plano do piso: junto à janela, no centro e junto à porta. Visualmente, percebe-se a coincidência nas tendências de variação das iluminâncias, com os maiores valores e variações ocorrendo próximo à abertura e reduzindo-se com o afastamento dela.

As iluminâncias medidas no ponto junto à janela, nas 25 ocasiões e em diferentes horários do dia, foram muito próximas (ver Figura 16), com erros médios inferiores a 3\%, com as medidas feitas no ambiente real um pouco acima das feitas no modelo físico em escala. Isso pode ser explicado por dois fatores: predominância da componente direta da luz natural; e pelo maior ângulo de visão do céu do sensor, que reduz o erro decorrente da variação da proporção das dimensões do sensor e da abertura, no modelo real e no em escala reduzida.

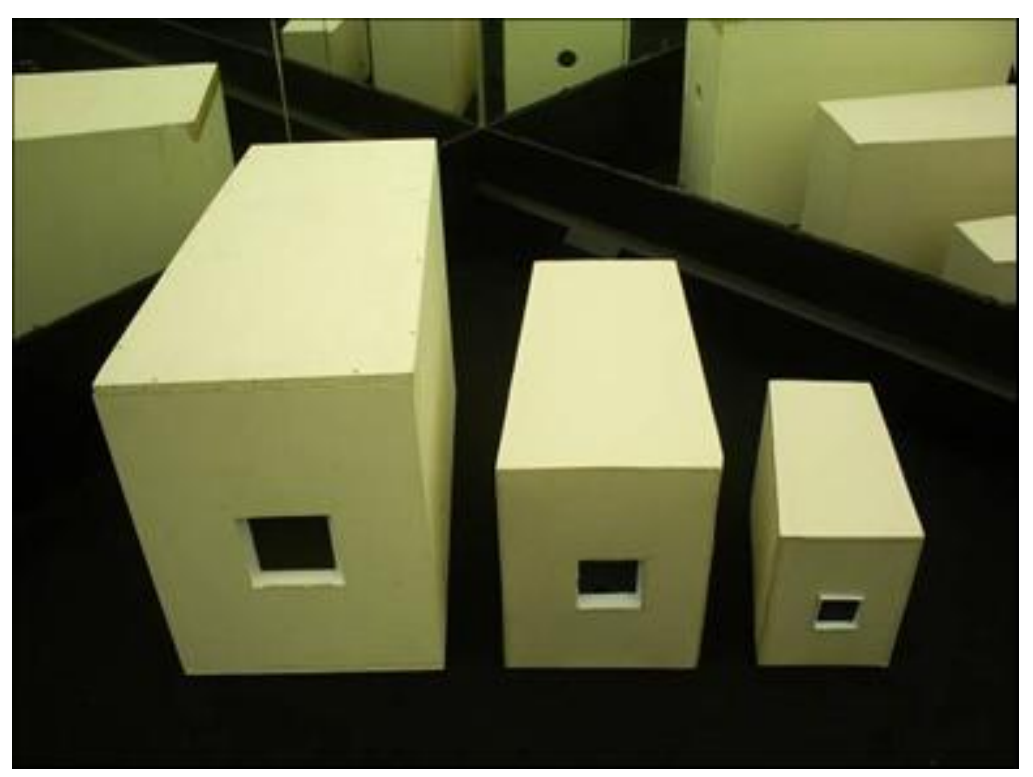

Figura 15 - Modelos arquitetônicos nas escalas 1:5, 1:75 e 1:10 


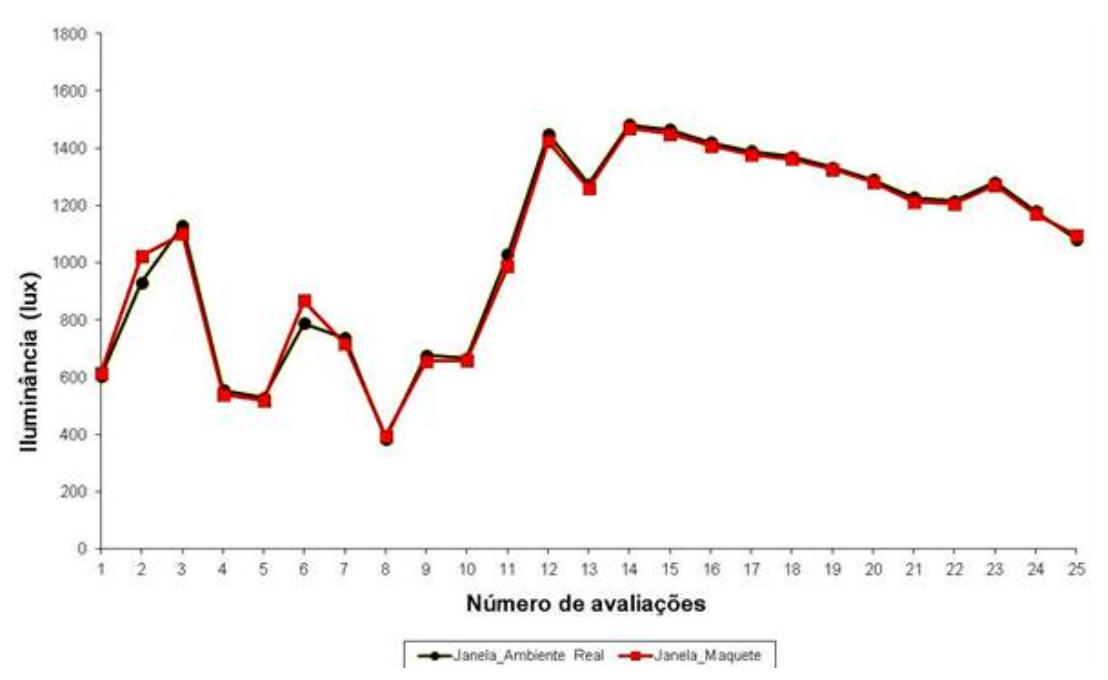

Figura 16 - Iluminâncias medidas no ponto junto à janela no ambiente real e no modelo em escala reduzida (maquete)

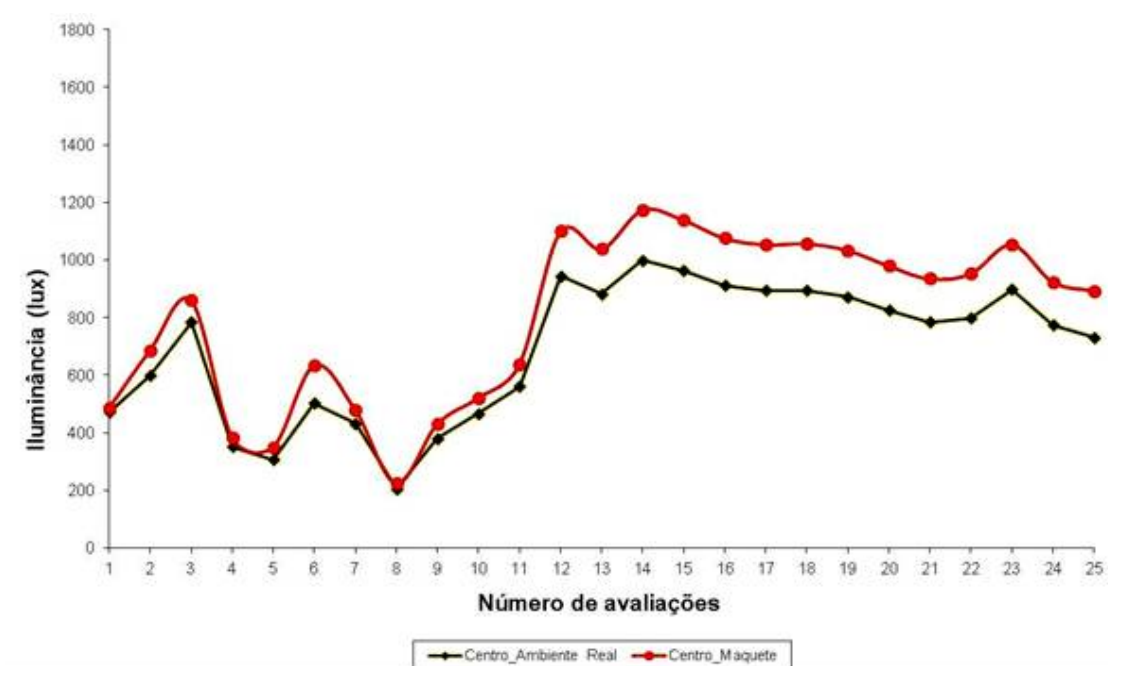

Figura 17 - Iluminâncias medidas no ponto do centro no ambiente real e no modelo em escala reduzida (maquete)

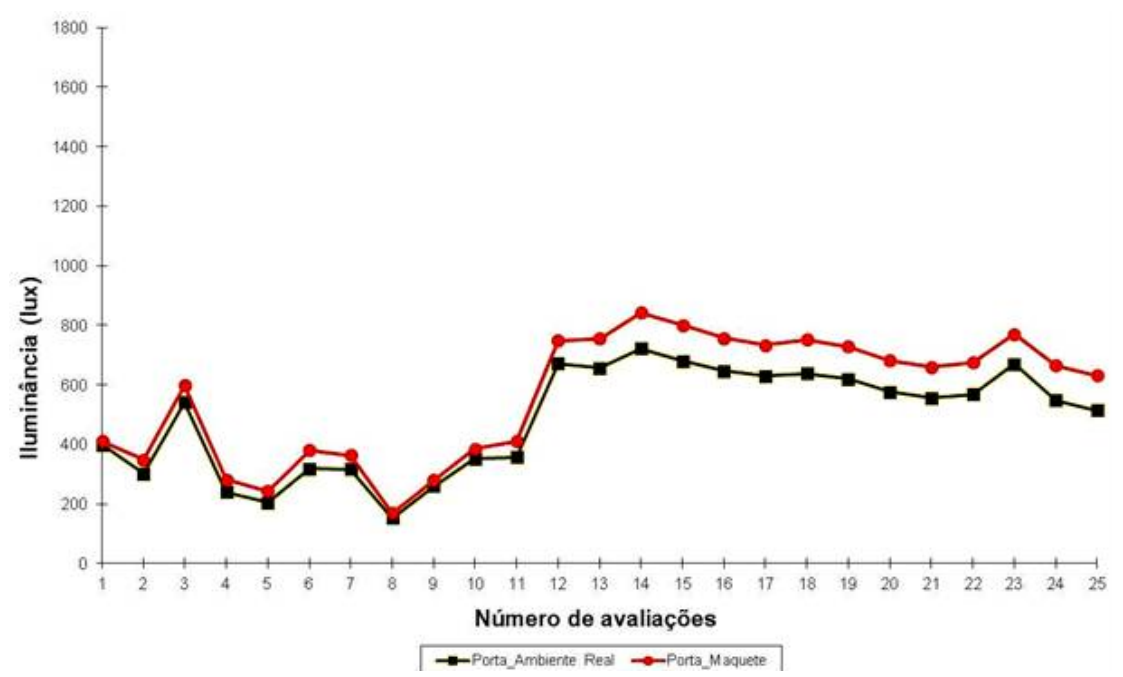

Figura 18 - Iluminâncias medidas no ponto junto à porta no ambiente real e no modelo em escala reduzida (maquete)

142 Pereira, F. O. R.; Pereira, R. C.; González Castaño, A. 
Já nos pontos do centro da sala e junto à porta (ver Figuras 17 e 18), as diferenças entre as iluminâncias aumentaram, especialmente a partir da avaliação 12, apresentando um erro médio variando de $15 \%$ a $25 \%$ até a avaliação 25 . A Figura 19 apresenta as medições da iluminância vertical externa tomada no plano da abertura durante um dos dias que geraram os valores das medições de 12 a 25 , onde se percebe uma variação nitidamente irregular da disponibilidade de luz natural, que pode ser atribuída a uma irregular e acentuada variação de brilho entre diversas porções do hemisfério celeste. Esse fato pode perfeitamente explicar os maiores valores de iluminância medidos e também pode ter sido a principal influência para as maiores diferenças deles em favor do modelo físico em escala. Com os pontos de medição mais afastados da abertura, seus campos de visão são dominados pelas superfícies internas (paredes e teto), resultando numa maior influência da componente da luz natural refletida internamente. Dessa forma, tanto as porções do céu com maiores brilhos visíveis pelas superfícies internas como as possíveis diferenças nas refletâncias dos diferentes materiais dos modelos reais e em escala podem ser a causa das diferenças encontradas.

Os erros médios das iluminâncias medidas foram calculados pela Equação 1 e plotados na Figura 20. As menores divergências encontradas, abaixo de $5 \%$, ocorreram nos sensores mais próximos à janela, conforme esperado, tanto na posição do piso como nas superfícies verticais, à direita e à esquerda. Os resultados do sensor no piso no centro da sala e junto à porta (mais afastados da janela) apresentaram as maiores divergências, em torno de $15 \%$ a $20 \%$ (ver Figura 20 ).

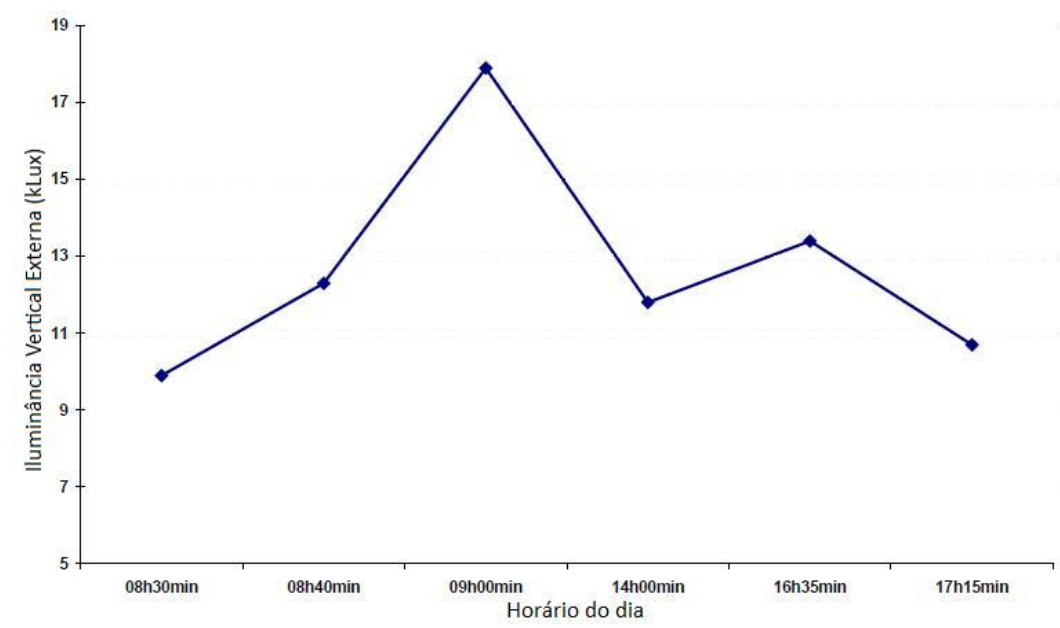

Figura 19 - Iluminâncias medidas no exterior com o sensor na posição vertical na orientação da abertura, no dia 12/04/2008 (um dos dias das medições de 12 a 25)

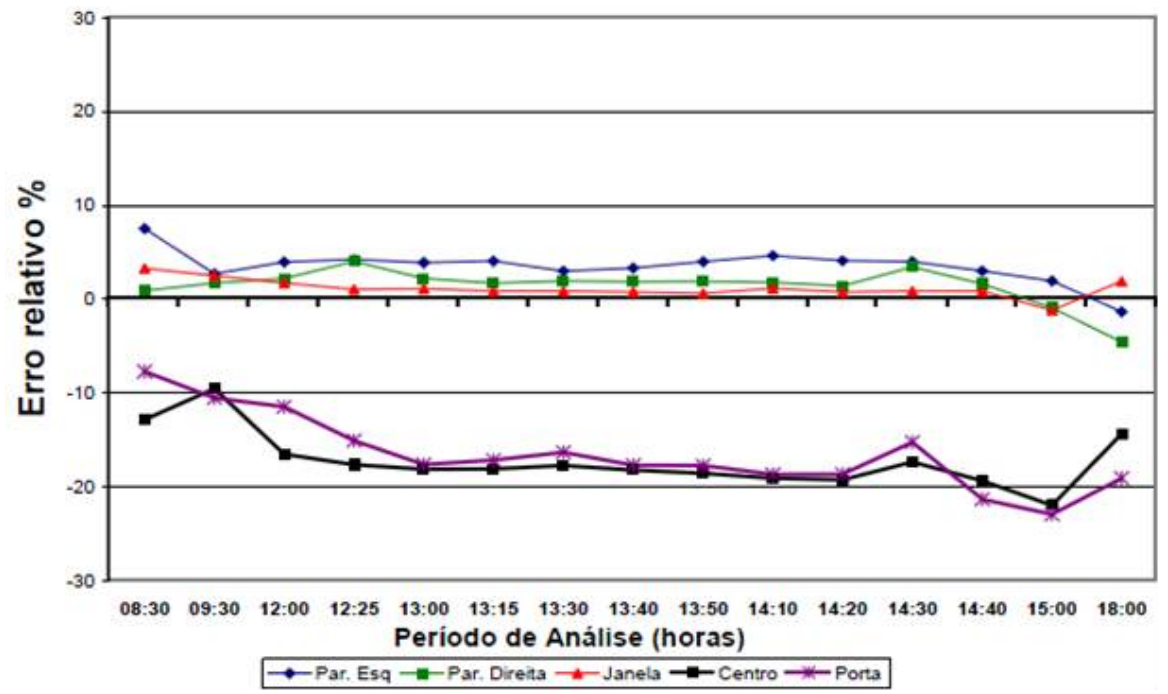

Figura 20 - Erro relativo entre o ambiente em escala e o real 
Além de as divergências serem quantitativamente menores junto à janela, os resultados mostram que as medições feitas no ambiente em escala subestimam as iluminâncias reais, fato que pode ser explicado pela maior área relativa dos sensores nos modelos reduzidos, o que modifica efetivamente o campo de visão dos sensores através da abertura. Nos pontos mais afastados da janela, os valores são superestimados, ou seja, são superiores às iluminâncias medidas no ambiente real. Nesse caso, a explicação mais provável reside nas possíveis diferenças das refletâncias entre paredes do ambiente real (rebocadas) e as do modelo em escala (madeira), que causam impacto na componente da luz refletida nas superfícies internas.

A Figura 21 mostra a frequência de ocorrência de erros relativos nas diversas faixas de erro. As ocorrências de erros no intervalo de $+/-5 \%$ foram de $92 \%$ para as medidas junto à janela, $88 \%$ na parede direita, e $80 \%$ na parede esquerda, enquanto os erros das medidas nos pontos mais afastados da janela situaram-se, em sua maioria, no intervalo de $-10 \%$ a $-20 \%$ (80\% para a porta e $76 \%$ para o centro).

Mesmo considerando-se a diferença de proporção entre a dimensão dos sensores e as dimensões das aberturas (ambiente real e em escala) e o fato de as medidas terem sido realizadas sob diferentes condições de céu real, a concordância entre os valores encontrados nas posições junto à abertura foi muito boa. As divergências encontradas nos pontos mais afastados da janela podem estar associadas à influência da componente da iluminação refletida internamente. Em relação a isso, cabe salientar que, apesar de ter sido usada a mesma cor, foram tintas distintas devido à natureza dos materiais, reboco fino no ambiente real e madeira de compensado lixada no ambiente em escala. Diferenças na refletância final e, especialmente, na distribuição da luz refletida internamente podem ser a causa dessa superestimação das iluminâncias no ambiente em escala reduzida.

\section{Comparação dos resultados em modelos físicos em diferentes escalas}

As medições foram realizadas no céu artificial do tipo “caixa de espelhos” do LabCon/ARQ, com uma iluminância média de aproximadamente 7.400 lux, na altura de referência do piso de $0,70 \mathrm{~m}$. A Tabela 1 apresenta os valores de iluminâncias e DF para cada um dos três pontos localizados no plano do piso (P1 - janela, P2 - centro e P3 - porta), para cada uma das três escalas.

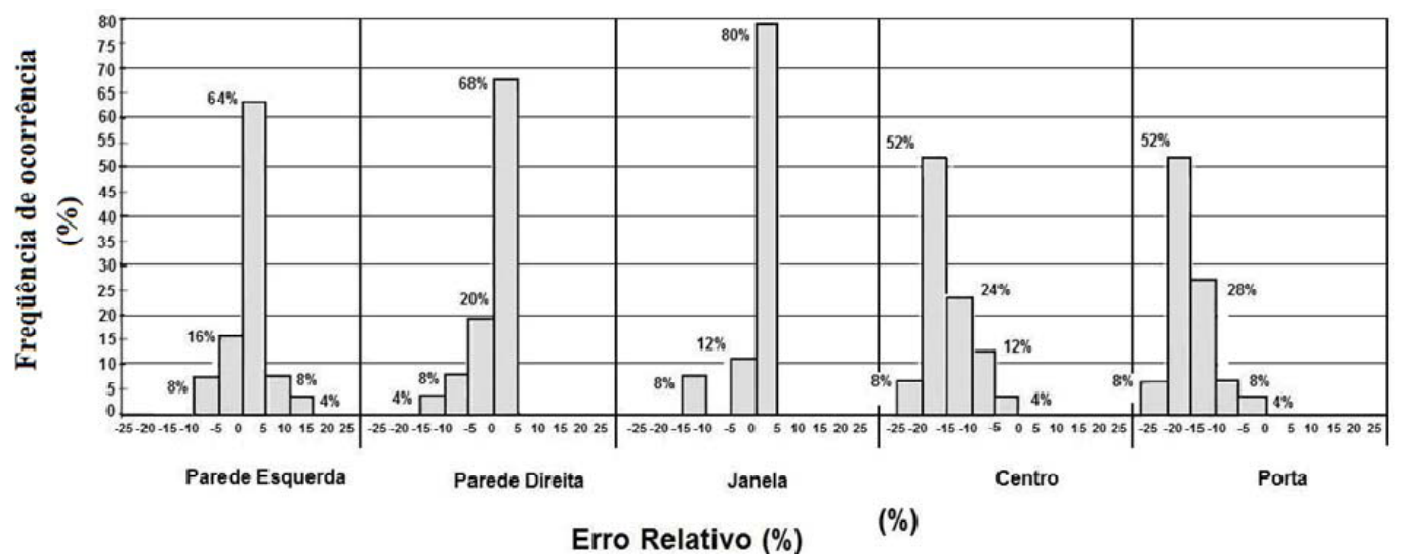

Figura 21 - Frequência de ocorrência dos erros relativos entre o ambiente em escala e o real

Tabela 1 - Dados de iluminância obtidos nos modelos arquitetônicos em escala

\begin{tabular}{c|c|c|c|c}
\hline \multicolumn{5}{c}{ AVALIAÇÃO POR ESCALAS } \\
\hline $\mathbf{E}_{\text {exterior }}$ & $\mathbf{7 . 4 2 5}$ lux & P1 & P2 & P3 \\
\hline \multirow{2}{*}{$1: 5$} & E (lux) & 220 & 136 & 92 \\
& DF (\%) & 2,96 & 1,84 & 1,24 \\
\hline \multirow{2}{*}{$\mathbf{1 : 7 , 5}$} & E (lux) & 214 & 130 & 90 \\
& DF (\%) & 2,88 & 1,75 & 1,21 \\
\hline \multirow{2}{*}{$\mathbf{1 : 1 0}$} & E (lux) & 210 & 128 & 89 \\
& DF (\%) & 2,83 & 1,72 & 1,20 \\
\hline
\end{tabular}

144 Pereira, F. O. R.; Pereira, R. C.; González Castaño, A. 
A Figura 22 apresenta a variação gráfica dos valores de DF (\%) para os três pontos nas três escalas distintas.

As análises das medidas obtidas mostraram que o modelo na escala 1:5 apresentou valores de DF superiores aos dos outros dois modelos. Os resultados dos modelos 1:7,5 e 1:10 mostraram-se muito próximos quando comparados com os do modelo 1:5. Essa condição pode ser associada ao fato de que o material do modelo na escala 1:5 é madeira compensada pintada, enquanto os modelos 1:75 e 1:10 foram construídos com papel Paraná, pintados com a mesma tinta. Assim, da mesma forma que as diferenças observadas entre 0 ambiente real e o ambiente em escala reduzida, as diferenças encontradas entre esses modelos de diferentes materiais podem ser decorrentes das variações na componente da luz refletida internamente.

Quantitativamente, as maiores diferenças foram de $6 \%$ no ponto P2 (centro) entre os valores dos modelos nas escalas 1:5 e 1:10. A discrepância média situou-se entre 3\% e $4 \%$.

Com esses resultados, entende-se ser possível afirmar que o efeito da escala não representa um erro significativo na avaliação e no cálculo de DF com modelos físicos em escala reduzida no interior do céu artificial do tipo “caixa de espelhos”, considerando que a divergência média dos valores que caracterizam a iluminação interna foi inferior a $4 \%$.

\section{Conclusões}

A partir dos resultados obtidos nas duas etapas do método de estudo proposto, é possível verificar que o procedimento experimental com modelos físicos em escala reduzida pode ser um método bastante confiável para simular quantitativamente as condições de iluminação natural no interior de edificações.

Os erros relativos entre os valores medidos no ambiente real e no modelo em escala foram inferiores a 5\%, exceto naquelas situações em que a componente refletida interna foi relevante. Nesses casos, a falta de garantia da obtenção das refletâncias iguais (em magnitude e distribuição) foi aparentemente a principal responsável pelos maiores erros, de até $20 \%$.

A influência do efeito de escala também não se mostrou significativa, pois divergências inferiores a $4 \%$ podem ser consideradas irrelevantes.

Entretanto, cabe salientar que certos cuidados na confecção dos modelos e na realização das medições são muito importantes e necessários, em especial no que tange à caracterização das propriedades ópticas das superfícies participantes, reprodução das condições de exposição dos modelos (entorno), precisão dimensional e procedimentos fotométricos.

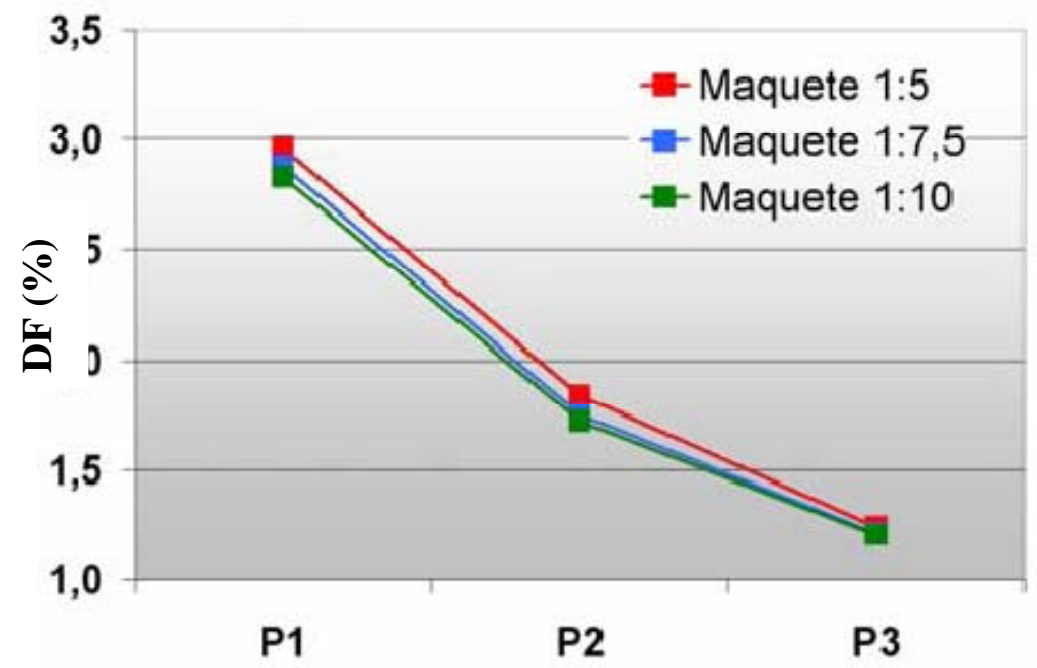

Figura 22 - DF (\%) medidos nos modelos arquitetônicos 1:5, 1:7,5 e 1:10 


\section{Referências bibliográficas}

ALMASY, P. [ID do banco de fotos: AL002431]. Disponível em:

<http://www.corbisimages.com/stock-photo/rightsmanaged/AL002431/le-corbusier-with-

architectural-model?popup=1>. Acesso em: 18 jan. 2012.

BAKER, N.; STEEMERS, K. Daylight Design of Buildings. London: James X James, 2002.

BODART, M.; DENEYER, A.; MOENSSENS, N. Guide Précis d'Aide à la Construction des Modeles réduits: pour utilisation et mesures sous ciel artificiel au CSTC. Centre Scientifique et Technique de la Construction, june 2004.

BODART, M. The New Belgian Artificial Sky and Sun and Its Validation. In: INTERNATIONAL ENERGY AGENCY TASK 31 SYMPOSIUM, Vancouver. Proceedings... Vancouver, 2004.

CANNON-BROOKES, S. W. A. Simple Scale Models for Daylighting Design: analysis of sources of error in illuminance prediction. Lighting Research and Technology, v. 29, n. 3, p. 135-142, 1997.

COOSKY, C. et al. "Limits of the sky": testing and evaluation of the current state-of-the art in mirror-box sky simulation. Departament of Architecture Unversity of Washington. Washington, 1989.

CORBIS IMAGES. [ID do banco de fotos: BE043029]. Disponível em:

$<$ http://www.corbisimages.com/stock-photo/rightsmanaged/BE043029/frank-lloyd-wright-standingbeside-architectural-model?popup=1 $>$. Acesso em: 18 jan. 2012.

EVANS, J. M.; BAROLDI, G. M.; MARMORA, M. I. Diseño y construcción de un cielo artificial tipo espejo. Avances en Energías Renovables y Medio Ambiente, v. 1, n. 1, p. 121-124, 1997.

GONZÁLEZ CASTAÑO, A. Avaliação e Calibração de Um Céu Artificial para Estudos de Iluminação Natural Com Modelos Físicos em Escala Reduzida. Florianópolis, 2007.

Dissertação (Mestrado em Arquitetura e Urbanismo) - Programa de Pós-Graduação em Arquitetura e Urbanismo, Universidade Federal de Santa Catarina, Florianópolis, 2007.

INTERNATIONAL ENERGY AGENCY. Daylighting Simulation: methods, algorithms, resources, solar heating and cooling programme. In: Task 21: systems programme, annex 29. December 2006.
KIM, K. S.; BOYER, L.; DEGELMAN, L. Daylighting Analysis Through Scale Model, Full Scale Measurements and Computer Analysis For a Texas A\&M University Campus Building. In: ANNUAL SYMPOSIUM "IMPROVING BUILDING ENERGY EFFICIENCY IN HOT AND HUMID CLIMATE", 2., Texas, 1985. Proceedings...Texas, 1985. p. 16-21.

LOVE, J. A.; NAVVAB, M. Daylighting Estimation Under Real Skies: a comparison of fullscale photometry, model photometry and computer simulation. Journal of the Illuminating Society, New York, v. 20, n. 1, p. 140-156, 1991.

MARDALJEVIC, J. A ‘Gold Standard’: dataset for the validation of illuminance predictions. In: INTERNATIONAL ENERGY AGENCY TASK 31 SYMPOSIUM, Otawwa. Proceedings... Ottawa: Montfort University, 2002.

MARDALJEVIC, J. Verification of Program accuracy For Illuminance Modeling: assumptions, methodology and an examination of conflicting findings. Lighting Research and Technology Journal, v. 36, n. 3, p. 217-242, 2004.

MOORE, F. Concepts and Practice of Architectural Daylighting. 2. ed. New York: Van Nostrand Reinhold, 1991.

NASPOLINI, V.; PEREIRA, F. O. R. Experimentando o Fenômeno da Iluminação Natural Através da Simulação Computacional em Edificações Emblemáticas. In: CONFERÊNCIA LATINO-AMERICANA DE CONSTRUÇÃO SUSTENTÁVEL; ENCONTRO NACIONAL DE TECNOLOGIA DO AMBIENTE CONSTRUÍDO, 10., São Paulo, SP, 2004. Anais... São Paulo: ANTAC, 2004. 1 CD-ROM.

NAVVAB, M. Scale Model Photometry Techniques Under Simulated Sky Conditions. In: ANNUAL CONFERENCE OF THE ILLUMINATING ENGINEERING SOCIETY OF NORTH AMERICA, 1995. Proceedings... New York: IESNA, summer, 1995. p 160-171.

PEREIRA, F. O. R. Iluminação Natural no Ambiente Construído. In: Encontro Nacional de Conforto do Ambiente Construído, 3., Gramado, 1995. Anais... Gramado: ANTAC, 1995. Apostila de curso de curta-duração ministrado no evento.

PEREIRA, R. C. Metodologia Para Avaliação de Ferramentas de Simulação de Iluminação Natural Através de Mapeamento Digital de Luminâncias. Florianópolis, 2009. Tese (Doutorado em Engenharia Civil) - Programa de Pós-Graduação em Engenharia Civil, Universidade Federal de Santa Catarina, Florianópolis, 2009. 
REINHART, C.; FITZ, A. Findings From a Survey on the Current Use of Daylight Simulations in

Building Design. Energy and Buildings, v. 38, n. 7, p. 824-835, jul. 2006.

\section{SCHILER, M. (Ed.). Simulating Daylight With}

Architectural Models. Los Angeles? Daylighting Network of North America, University of Southern California, 1987.
THANACHAREONKIT, A.; ANDERSEN, M.; SCARTEZZINI, J-L. Comparing Daylighting Performances Assessment of Buildings Within Scale Models and Test Modules. Journal Solar Energy, v. 79, p. 107-220, 2005.

Revista Ambiente Construído

Associação Nacional de Tecnologia do Ambiente Construído

Av. Osvaldo Aranha, 99 - 3o andar, Centro

Porto Alegre - RS - Brasil

CEP 90035-190

Telefone: +55 (51) 3308-4084

Fax: +55 (51) 3308-4054

www. seer. ufrgs. br/ ambienteconstruido

E-mail: ambienteconstruido@ufrgs.br 